\title{
A Sectoral Supply-Side Model to Assess the Impact of Labour Market Reforms in Malta
}

\author{
Brian Micallef ${ }^{1}$ \\ ${ }^{1}$ Manager, Research Office, Central Bank of Malta, Malta \\ Correspondence: Brian Micallef, Research Office, Central Bank of Malta, Castille Place, Valletta, Malta. Tel: \\ 356-2248-7922. E-mail: micallefb@centralbankmalta.org
}

Received: February 14, 2017

Accepted: March 1, 2017

Online Published: March 15, 2017

doi:10.5539/ijef.v9n4p105

URL: https://doi.org/10.5539/ijef.v9n4p105

\begin{abstract}
The Maltese economy recovered strongly after the financial crisis of 2009 and its labour market kept the pace with the rapid evolution of the economy since EU membership. This labour market resilience has to be seen in the context of important labour market reforms undertaken in recent years that have played an important role in raising the Maltese economy's potential growth rate. This paper presents a novel modelling approach to characterize the supply side of the Maltese economy. The model consists of a matrix transformation method using data on demography, education, labour market statistics from survey and administrative sources and gross value added from the National Accounts. This framework is used to quantitatively assess the economic impact of specific labour market policies, such as those pertaining to education and re-training, active labour market policies and inflows or outflows of workers from the labour market.
\end{abstract}

Keywords: supply-side, labour market, reforms, Malta

\section{Introduction}

From an economic perspective, the supply-side is the ultimate determinant of the economy's output, incomes and expenditure. An analysis of the supply side gives an indication of the fundamental underlying capabilities of the economy, free from the distortions which may be created by temporary aggregate demand shocks.

In a small and open economy as Malta, there are additional considerations that make the analysis of the supply side essential. First, domestic demand typically impinges on the balance of payments to a stronger degree. Second, capacity constraints and production cost issues are typically far more important limiting factor of export growth than foreign demand, of which Malta can only potentially serve but a tiny fraction. Third, equilibrating factors, including price and wage flexibility, may not operate sufficiently well in a small economy where it is easier for economic agents to acquire monopolistic power and where there is a large element of imported inflation. Moreover, the performance of small economies is often subject to exogenous shocks, which would typically originate from events in specific sectors of activity and can be better analyzed as such.

The Maltese economy recovered strongly after the financial crisis of 2009 and its labour market kept the pace with the rapid evolution of the economy since EU membership in 2004. Both the unemployment rate and estimates of the structural rate of unemployment were hardly affected by the crisis, reaching historical lows in 2015 (Micallef, 2017). The labour supply increased sharply, driven by reforms targeted to increase the participation rate of females as well as an influx of foreign workers. The share of the foreign workers increased from less than $2 \%$ in 2004 to almost $11 \%$ by 2014 (Grech, 2015). The increase in the supply of labour has eased labour shortages in selected sectors and kept wage pressures contained. In addition, the pension reforms of 2006 and 2015 were intended to encourage older workers to remain active for a longer period of time over the coming years (Grech, 2016).

This labour market resilience has to be seen in the context of important labour market reforms undertaken in recent years that have played an important role in raising the Maltese economy's potential growth rate. Over the last decade, Malta registered the largest increase in the female participation rate among EU countries as a result of numerous initiatives intended to attract more females to the labour market, including tax incentives and free child care centers (Micallef, 2015). Targeted training schemes were introduced to strengthen the employability prospects of certain target groups, including through the provision of training and on-the-job experiences, while 
a national apprentice scheme was launched to strengthen the link between academia and the business community. Initiatives were also taken to reduce the reliance of long-term unemployed on the unemployment benefits and facilitate their integration in the labour market, for instance, by gradually tapering-off social benefits. Measures were also introduced to curtail abuse of the unemployment register by reducing undeclared work and encourage people to enter the formal economy.

Against this background, this paper makes a methodological and empirical contribution to the literature. On the methodological front, it presents a novel modelling approach consisting of a matrix transformation method using data on demography, education, labour market statistics from survey and administrative sources and gross value added from National Accounts. On the empirical front, this modelling approach allows a more focused economic assessment of specific policies, including those aimed at particular sectors. A number of studies have attempted to estimate the impact of individual reforms and policies on the Maltese economy's supply side potential (Micallef, 2015; Grech, 2015, Grech, 2016). All of these studies, however, use an aggregate approach and abstract from developments at a sectoral level. The empirical model combines demographic and sectoral information with the characteristics of the labour force, such as age and education levels, thereby allowing for an assessment of a broad range of labour market policies such as those pertaining to education and re-training, active labour market policies and inflows or outflows of workers from the labour market.

The rest of the paper is structured as follows. Section 2 provides a brief description of the mainstream approaches used in the literature to measure potential output and estimate the impact of structural reforms in the labour market. Section 3 provides a snapshot of the sectoral developments in the Maltese economy over the last few years, setting the background for the subsequent sectoral analysis. Section 4 describes in detail the proposed model and the variables used. Section 5 presents a number of simulations to assess the properties of the model. Section 6 discusses the results and section 7 concludes and provides some avenues for further research.

\section{Literature Review}

A wide variety of approaches have been proposed in the literature to estimate the supply side capacity of an economy, ranging from simple filtering techniques to state-of-the-art macroeconomic models. Despite this wealth of options, however, the literature is still inconclusive on the 'best' methodology to estimate this level of output, largely because the supply side potential is an unobservable variable and different approaches tend to provide different results.

The preferred methodology will, to a great extent, depend on the policy priority for which the supply side potential is being evaluated (Cotis et al., 2003). For instance, a study intended to compare a group of countries for surveillance purposes (e.g. for the determination of the cyclically adjusted fiscal balance in the context of the EU's Stability and Growth Pact) may require a different approach than a study whose objective is to assess the economy's potential from a sectoral perspective. Those who subscribe to this point of view have argued that, apart from satisfying a set of 'core' requirements (e.g. transparency, consistency with economic theory, the size of revisions and estimates of uncertainty), the ideal approach should also take into consideration a set of 'user specific' requirements (e.g. the quality and frequency of the data available, the ability to detect structural changes and the reliability of the estimates at the end of the sample).

Traditionally, methods to estimate potential output have been classified under two broad categories, those that focus purely on statistical and filtering techniques and those that rely more on economic theory (Note 1). The creation of semi-structural or multivariate approaches, which combine traditional filters with economic relationships, suggests that a continuum of methods, rather than two distinct classes, is a more accurate description of the state of play of the literature on the topic. Further recently developed routes to the estimation of potential output are Dynamic Stochastic General Equilibrium (DSGE) models (Smets \& Wouters, 2007). The latter present a theoretically elegant approach which assumes that economic agents optimize their behaviour, while also taking into account nominal rigidities and structural features one encounters in the real world.

Whichever methodology and level of sophistication are used, policymakers should bear in mind that the supply side potential of an economy remains an unobservable variable. Estimates obtained from any single method should always be cross-checked with estimates obtained from alternative methodologies in order to ensure the consistency and reliability of the results.

Estimates of the Maltese economy's supply capacity are typically estimated using the production function approach or a multivariate approach. Grech and Micallef (2015) calculate Malta's potential output growth using a Cobb-Douglas production function for the period between 1995 and 2014. The labour input is decomposed in four key variables, the working age population, the trend participation rate, the non-accelerating inflation rate of unemployment (NAIRU) and trend hours worked. Micallef (2016) estimates potential output, NAIRU and the 
corresponding gaps using a multivariate filter that includes long-standing relationships in economic theory such as the Phillips Curve and Okun's Law. Both studies find that the Great Recession of 2009 had an adverse impact on Malta's potential growth rate but this has recovered strongly after the crisis, exceeding the pre-crisis growth rate by 2013. In particular, Grech and Micallef (2015) find that the contribution of labour increased significantly in recent years owing mainly to the rise in the participation rate and, to a lesser extent, the decline in structural unemployment, which more than outweighed the unfavourable effects of an ageing population.

A number of studies have focused on the impact of selected labour market reforms in Malta. Using an aggregate and a cohort approach, Micallef (2015) estimates that around half the increase in the female participation rate in Malta between 2008 and 2014 was attributable the targeted reforms to attract more women to the labour market. Grech (2016) evaluates the effects of the first change in the eligibility age from the 2012 pension reform, which will incrementally increase the retirement age to 65 for both genders by 2026 . Using employment and beneficiaries data and extrapolating to 2026, he estimates that the pension age rise could lead to a $3.6 \%$ increase in the potential labour force. Grech (2015) documents the changing profile of the migrant workers in Malta, which increased from $1 \%$ of the workforce in 2000 to $10 \%$ by 2014 . He estimates the migrant workers contributed around 0.6 percentage point to potential output growth between 2010 and 2014. Bugeja et al. (2016) use EUROMOD, a tax-benefit micro simulation model to simulate the redistribution impact of the labour market reforms announced in the 2016 budget in Malta.

An extensive and growing literature finds a positive relationship between structural reforms and growth, especially in the long run. Most of the studies are conducted within the context of a general equilibrium framework with a monopolistic competitive setup, with the structural reforms typically focusing on product and labour markets. Within this framework, the impact of structural reforms is assessed through a reduction in mark-ups, with the latter being inversely related to the degree of competition within these markets (Blanchard \& Giavazzi, 2003; Bayoumi et al., 2004; Everaert \& Schule, 2008; Forni et al., 2010; Gomes et al., 2011; Lusinyan \& Muir, 2013). Micallef (2013) applies a large scale multi-country DSGE model calibrated for Malta to assess the impact of structural reforms in domestic product and labour markets. This study finds that a 10 percentage point reduction in services and labour market mark-ups raises GDP by more than 5\% in the long-run, with the impact of labour market reforms being more pronounced than that of services reforms.

However, it has to be acknowledged that the mainstream approaches typically require levels of data and modelling complexity which adversely affect the credibility with which they can be actually applied to small economies in general, and the Maltese economy in particular. For instance, the calibration of dynamic general equilibrium models typically depends on empirical analysis at the micro level, which is very scarce in Malta. In addition, these models are unable to assess the impact of the reforms at a detailed sectoral level and the ensuing reallocation of resources from one sector to another, focusing instead on broad categorizations such as the 'tradable' and 'non-tradable' sector.

In light of these limitations and the evolving characteristics of the Maltese economy, this study proposes a novel approach in modelling the supply-side capacity of the economy that relies mostly on sectoral labour market and value added data which are readily available. This approach is then applied to assess the impact of specific labour market reforms. A review of developments as indicated by sectoral data for the labour market and value added is provided next.

\section{The Model}

\subsection{General Outline of the Model}

The approach used to obtain a sectoral model driven by supply-side issues for Malta is described in Figure 1. The chart distinguishes between exogenous variables, which are the inputs that need to be given to the model for it to operate, the endogenous variables, i.e. those for which the model would produce results and the behavioural relationships, which constitute the processes from model inputs to outputs.

The model proposed is relatively simple in terms of the number of variables, behavioural relationships and degree of endogeneity of the model (i.e. the flow of relationships is mainly unidirectional with very limited feedback effects). This approach gives a greater degree of control on the model, which does not run risks of producing inexplicable results through simultaneous relationships which are not well-understood. Overall, it is considered that having a relatively large extent of exogenous inputs is essential in a supply-side model where changes are often of a step, rather than of an incremental magnitude.

The model runs with data for 2013 and is based on the assumption that the Maltese economy was operating at a level which was relatively close to potential during that year (Grech \& Micallef, 2016). All the data was obtained 
from the National Statistics Office (NSO). Labour market data was obtained from the Labour Force Survey. Population and education data were obtained from the NSO on the basis of extrapolations from the Census. Sectoral value added data was obtained from National Accounts statistics.

\section{Proposed Structure of the Model}

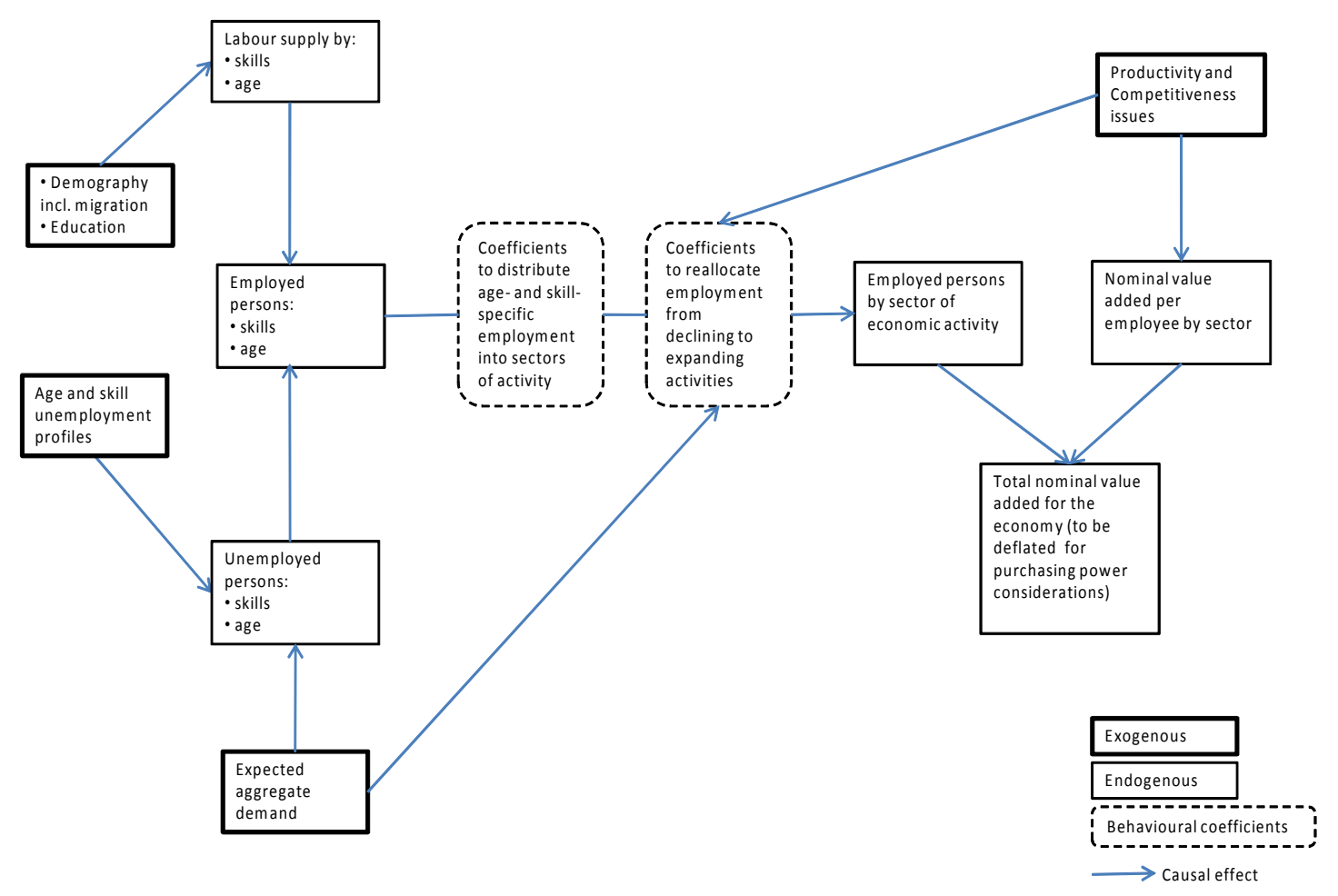

Figure 1. Proposed structure of the model

The model features three main groups of exogenous inputs: (i) demographic and education indicators; (ii) age and skill unemployment profiles; and (iii) aggregate demand. A description of the exogenous variables, including their derivations, is found below.

The principal endogenous variables, which constitutes the main outputs of the model, are the following: (i) labour supply categorized by skills and age; (ii) unemployed persons categorized by skills and age; (iii) employed persons categorized by skills and age; (iv) employed persons categorized by sector of activity; (v) value added per employee categorized by sector of activity; and (vi) total value added for the economy.

\subsection{Estimation}

Behavioural coefficients were derived by a matrix transformation method, which was used to transform two sets of data. First, it was applied to transform data on demography and education into labour supply categorized into skills and age, and then to transform employment data categorized into skills and age into a categorization by sector of economic activity.

The matrix transformation exercise involves the estimation of a transformation matrix based on a simple minimization of least squares procedure. If $\mathrm{X}$ is a matrix of exogenous inputs (e.g. demographic data categorized by age and education level) and $\mathrm{Y}$ is a matrix of endogenous results derived from it (e.g. labour supply categorized by age and skills levels), a linear relationship between the two matrices is specified:

$$
Y=X \beta+r
$$

where $\beta$ is a matrix which transforms $\mathrm{X}$ into $\mathrm{Y}$ and $\mathrm{r}$ is a vector of residuals. The matrix $\beta$ is estimated by a simple Ordinary Least Squares estimator $\widehat{\beta}$ where: 


$$
\hat{\beta}=\left(X^{T} X\right)^{-1} X^{T} Y
$$

and the vector of residuals estimated by means of $\hat{r}$ where:

$$
\hat{r}=Y-X \hat{\beta}
$$

The effects of changes in the exogenous matrix $\mathrm{X}$ on the endogenous matrix $\mathrm{Y}$ can be then estimated by means of:

$$
Y=X \hat{\beta}+\hat{r}
$$

This modelling exercise can be undertaken to varying extents of detail, as represented by considerations regarding the number of sectors of economic activity, the number of labour market age and skill categories, the extent of productivity and competitiveness issues and their impacts on the restructuring coefficients.

At an initial level, the modelling exercise was kept relatively simple. Sectors of economic activity were grouped into the six sectors considered in the next section. For the purpose of labour market data, six age brackets, ten levels of skills and three levels of educational achievement were considered. No consideration for firms of different sizes and competitiveness issues were made.

\subsection{Description of the Model}

The basic structure of the model is to consider inputs regarding demography and education in order to derive the supply of labour categorized by skills and age, which is an essential supply-side input in the Maltese economy. The demographic data includes new and returned workers, migrants and retirees, while the education data comprises both school-age and life-long achievements.

Age and skill unemployment profiles, in conjunction with aggregate demand, allow the derivation of unemployment rates categorized by skills and age. Ideally, it is expected, rather than historic, aggregate demand that is the relevant determining variable in order to take labour supply bottlenecks into consideration.

The combination of labour supply and unemployment rate results enables the derivation of the amount of employed persons categorized by skills and age. These were then distributed into different sectors of economic activity as conditioned by the latter's requirements for labour of specific skills and age profiles by a matrix transformation method, taking also into account the patterns of growth and decline of specific sectors of activity.

The combination of employment by sector of activity and value added per employee yields the aggregate value added of the economy, which is better considered in nominal rather than in real terms to take account of fluctuations in product prices which would impact on performance and profitability, including developments in the terms of trade (Note 2).

\subsection{Description of the Variables}

An analysis of the variables used as inputs in the model provides important insights on the supply-side capacity of the Maltese economy.

\subsubsection{Demography and Education}

The dataset includes six age brackets (15-24, 25-34, 35-44, 45-54, 55-64 and 65+) and three levels of educational attainments. No considerations were given to the population below 15 years of age. Education levels are based according to the International Standard Classification of Education (ISCED). Level 1 of the educational attainment relates to ISCED 0,1 and 2 categories, relating to primary and lower secondary levels of education (i.e. compulsory education), while Level 2 (ISCED 3 and 4) and Level 3 (ISCED 5 and 6) are associated with post-secondary and tertiary education, respectively.

The Maltese population aged above 15 years of age amounted to 352,746 in 2013. The working-age population, defined as the number of citizens aged between 15 and 64, stood at 284,035. The old-age dependency ratio stood at $24.2 \%$ in 2013 , up from $18.5 \%$ in 2007.

As at 2013 , around $61 \%$ of the population had accomplished only a compulsory level of education. The share of those with post-secondary and tertiary level of education stood at around $24 \%$ and $15 \%$, respectively. While the education attainment of the Maltese population is still low by European standards, it has gradually improved over the last few years. For instance, in 2007, the share of the population with a compulsory level of education stood at $71 \%$, while only $11 \%$ had a tertiary level of education.

\subsubsection{Employment}

The model features two sets of employment matrices, one categorized by skills and age, and another one categorized by skills and sectors of economic activity. In 2013, total employment stood at 175,472. 
The skill category follows the International Standard Classification of Occupations (ISCO) classification of the International Labour Organization (ILO). Skill category 1, referred to as 'High' skilled, refers to ISCO categories 1,2 and 3 , which covers legislators, senior officials, managers, professionals, technicians and associate professionals. Skill category 2, referred to as 'Medium' skilled, refers to ISCO categories 4, 5, 6 and 7. This category includes clerks, service workers, sales workers, skilled agricultural and fishery workers and craft and related trade workers. Finally, skill category 3, referred in the text as 'Low' skilled, refer to ISCO categories 8 and 9 , covering plant and machine operators and assemblers and elementary occupations. The armed forces are included in skill category 2.

Those employed in 'medium' skilled jobs constitute the largest share, at around $44 \%$, while those in 'high' and 'low' skilled jobs stood at $41 \%$ and $16 \%$, respectively.

The largest number of people was employed in the services sector. In 2013, employment in the services sector, including public administration, stood at $77 \%$ of total employment. The share of people working in industry stood at $15 \%$, while the shares of construction and agriculture stood at $6 \%$ and $1 \%$, respectively.

Figure 2 shows that there is a considerable degree of heterogeneity in the skills required at the sectoral level. More than half the workers in other market services (which include ICT, finance and insurance, professional and technical activities and the remote gaming industry) and the public administration, including health and education, are employed in high skilled positions. Similarly, more than half the workers in agriculture and construction are employed in 'Skilled agricultural and fishery workers' and 'Craft and related trades workers', respectively, both of which are classified as 'medium' skilled jobs. In industry, the shares are more evenly distributed compared to the other sectors. The share of 'low' skilled jobs in the latter sector amounted to 33\% although even in this case, the largest share constitute 'Plant and machine operators and assemblers', most of whom have valuable firm and machine specific skills.

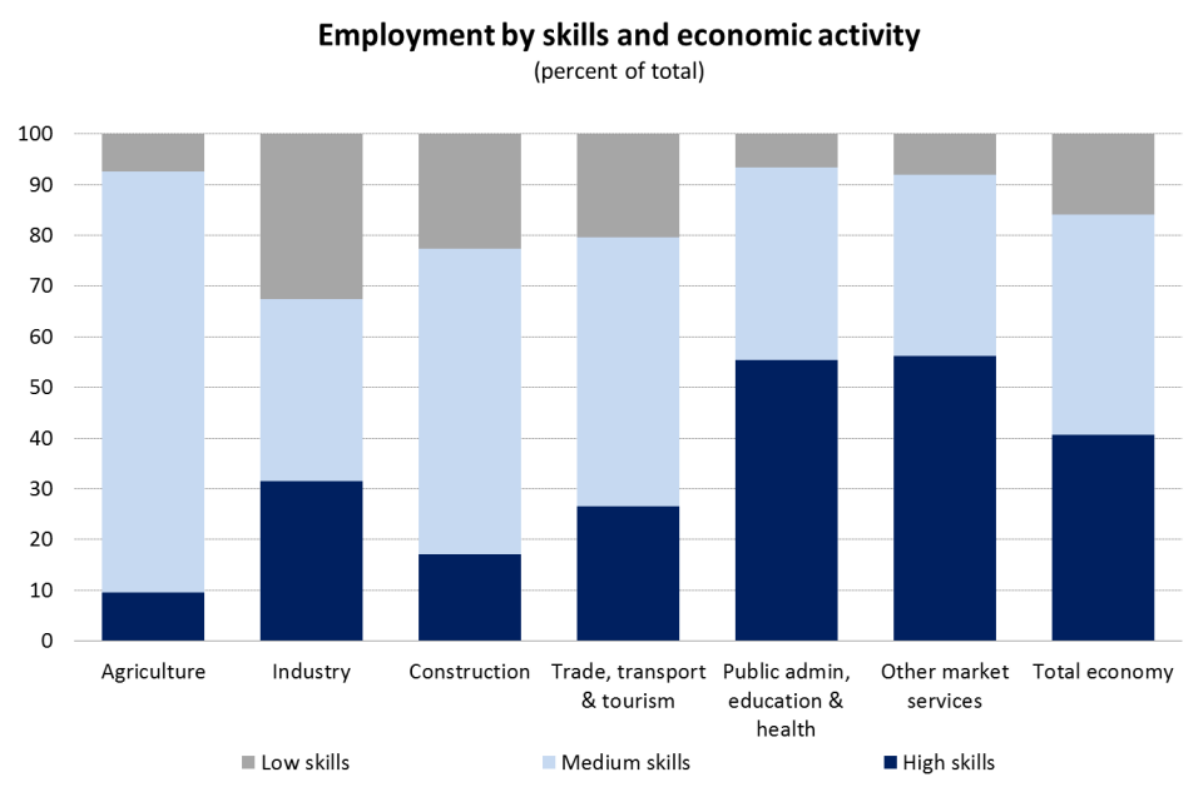

Figure 2. Employment by skills and economic activity

\subsubsection{Unemployment Categorized by Age and Skills}

The number of unemployed stood at 11,944 in 2013. More than half of those unemployed were searching for medium skilled jobs, with the largest two categories being 'Service workers and shop and sales workers' and 'Clerks'. The share of those searching for 'low' and 'high' skilled jobs amounted to $23 \%$ and $22 \%$, respectively.

As regards the age profile, by far the largest share of those unemployed was made up of people less than 34 years of age. This category constituted around $65 \%$ of total unemployed. The share of those between 35 and 54 years stood at $29 \%$, while those over 55 years of age only amounted to around $6 \%$.

\subsubsection{Labour Supply Categorized by Age and Skills}

The labour supply, which was derived from the combination of the employment and unemployment figures, stood at 187,416 in 2013. 
The activity rate, defined as the ratio of the labour supply to the working-age population (15-64), stood at $66 \%$ in 2013. The employment rate, defined as the ratio of those in employment to the working-age population, stood at $61.8 \%$. Furthermore, while the old-age dependency ratio stood at $24 \%$ in 2013 , the ratio of the actual number of people that are active in the labour market to the old aged citizens stood at $36.7 \%$.

\subsubsection{Aggregate Demand}

In the absence of a suitable proxy for expected aggregate demand, the relationship between unemployment and economic activity was estimated using Okun's Law. More specifically, the difference version of Okun's Law, which related the change in the unemployment rate to real GDP growth was estimated using data for the period between 2000 and 2015. Okun's coefficient stands at around 0.2, in line with Micallef (2017). According to this equation, the rate of output growth consistent with a stable unemployment rate is estimated at $2.1 \%$, which is broadly in line with the Maltese economy's potential growth rate over the sample period (Grech \& Micallef, 2015).

\subsubsection{Gross Value Added per Employee by Sector}

This variable was obtained by dividing the sectoral GVA by the number of employees in each sector. In 2013, the average GVA per employee in Malta stood at $€ 37,405$.

There is substantial heterogeneity in the sectoral GVA per employee. The highest GVA is recorded in other market services, at $€ 57,800$ per person employed. The latter category includes the remote gaming industry, finance and insurance, ICT as well as the professional, technical, scientific and real estate sectors. The GVA per employed person in the five remaining sectors stood lower than the national average. In 2013, the performance of these sectors ranged from around $12 \%$ below-average in industry to $30 \%$ lower in the construction sector. The performance of the construction sector is difficult to explain, especially in light of the importance of this sector to the Maltese economy. One explanation for this result could be the presence of significant under-reporting in this sector, which anecdotal evidence suggests is characterized by practices such as bartering, which are hard to capture.

\section{Simulating the Impact of Different Labour Market Policies}

The properties of the model are assessed through six different simulations. The simulations are intended to capture the changes in the sectoral employment in relation to shocks in the exogenous variables. The simulations are not calibrated to replicate any of the reforms undertaken by the authorities in recent years but to illustrate the properties of the model through hypothetical but realistic scenarios representing changes in education, demographics and labour market policies. The combination of the changes in sectoral employment with the nominal value added per employee in the respective sector yields the total change in the nominal value added for the Maltese economy.

The simulation results are presented in the form of charts. Each chart shows the percentage change with respect to the baseline scenario, both in terms of employment and GVA. The change with respect to the baseline scenario can be interpreted as the effect on the economy's supply capacity of the particular shock in question.

Finally, a word of caution regarding the interpretation of the simulation results is in order. The model builds on the assumption that the economy was operating at its potential in 2013. Although this may hold for the Maltese economy as a whole, it may not hold in each and every sector of economic activity. That said, erratic changes at the sectoral level tend to be smoothed out at the national level.

\section{Scenario 1: Shift towards higher education}

The first scenario is associated with the provision of tertiary educational skills to a pool of human resources that previously only possessed post-secondary education. This scenario is represented by a shift equivalent to $1 \%$ of the labour supply from Educational Level 2 to Level 3. In terms of the age distribution, the scenario is biased towards the younger age cohort, with $60 \%$ affecting the age category $15-24,30 \%$ those between $25-34$ and $10 \%$ those in the 35-44 cohort. 


\section{Scenario 1: Shift towards higher education}

(percentage change difference from baseline)

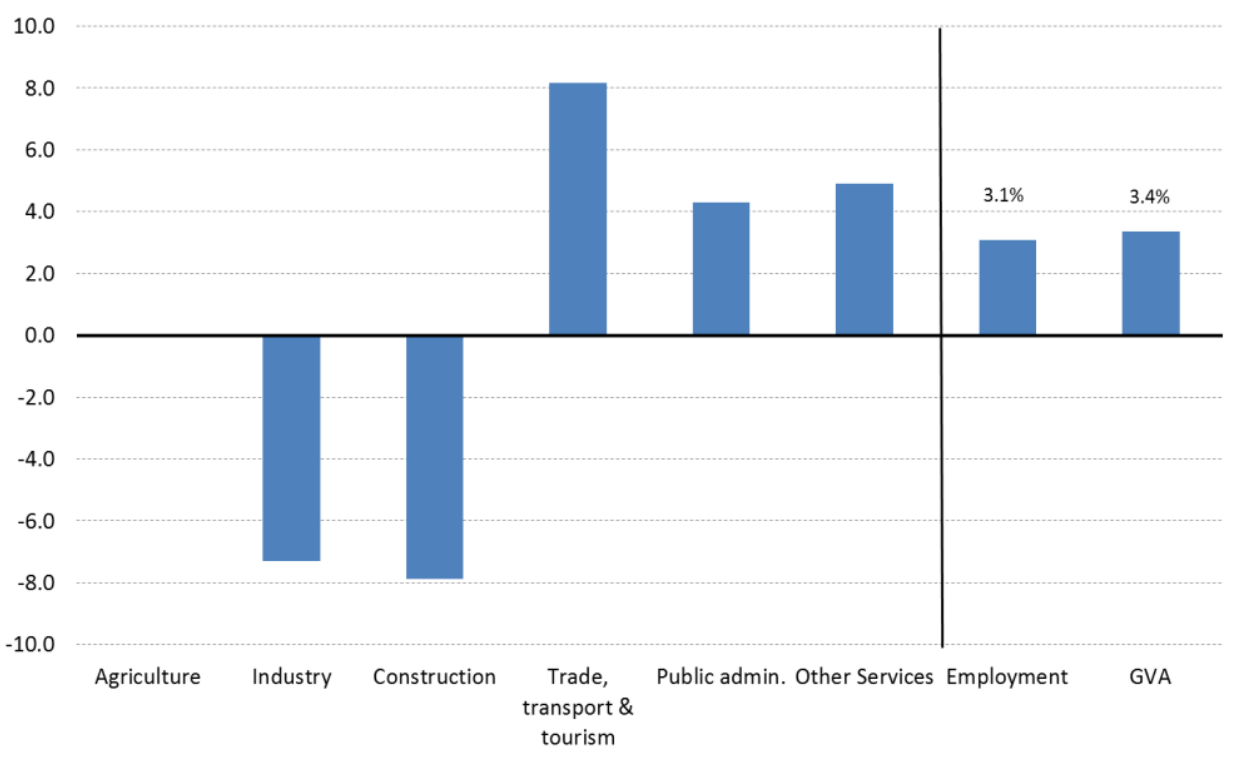

Figure 3. Shift towards higher education

Compared to the baseline scenario, total employment increases by $3.1 \%$, while GVA increases by $3.4 \%$. In general, this shock brings about a reallocation of resources from industry and construction towards the services sector. The reallocation leads to an increase in employment compared to baseline, while the increase in GVA is due to productivity enhancement as resources are shifted from low productive to high productive sectors, especially those in other market services. The latter is in line with findings using firm-level data (Lopez-Garcia et al., 2015).

\section{Scenario 2: Re-training}

Retraining is the process of learning new skills, often in response to changes in the structure of an economy. This process is very important in an economy characterized by rapid restructuring so that workers learn new skills in order to relocate from declining industries towards expanding ones. With the advent of globalization and the drive towards more flexible and leaner organizational structures, this process is becoming increasingly important even at the firm level. At this level, retraining is associated with the concept of multi-skilling, where an employee is trained to perform a range of particular tasks within the same organization. This concept has been increasingly employed by individual firms as part of their restructuring processes (Micallef \& Caruana, 2015).

In the model, retraining is associated with a shift equivalent to $1 \%$ of the labour force from Education Level 1 to Level 2. In terms of the age distribution, the scenario is biased towards the older age cohort, with $50 \%$ affecting the age category $34-44,30 \%$ those between $25-34$ and $20 \%$ those in the 15-24 cohort.

In response to this shock, both employment and output increase by $0.2 \%$ compared to the baseline scenario. At the sectoral level, caution is warranted in interpreting the winners and losers from this shock. Construction is the biggest winner, mainly due to the fact that more than half the workers in this industry have jobs with a 'medium' level of education and therefore are likely to benefit from a shift towards a higher level of education. The same applies to the agricultural sector. The skills required in these two industries are however very specific and it is unlikely that the gains proposed by this simulation for construction and agriculture will be realized in practice. The increase in construction could be interpreted to reflect efforts to shift employment from the informal to the formal economy as workers are awarded with formal qualifications for their skills. On the contrary, the gains by the other market services are more realistic as it increases the supply of potential employees that could assist the high skilled categories in this sector.

The most striking aspect of this simulation is that both the extent of the sectoral reallocation as well as the overall gains in employment and output are much smaller compare to the same shock of similar magnitude in Scenario 1. 


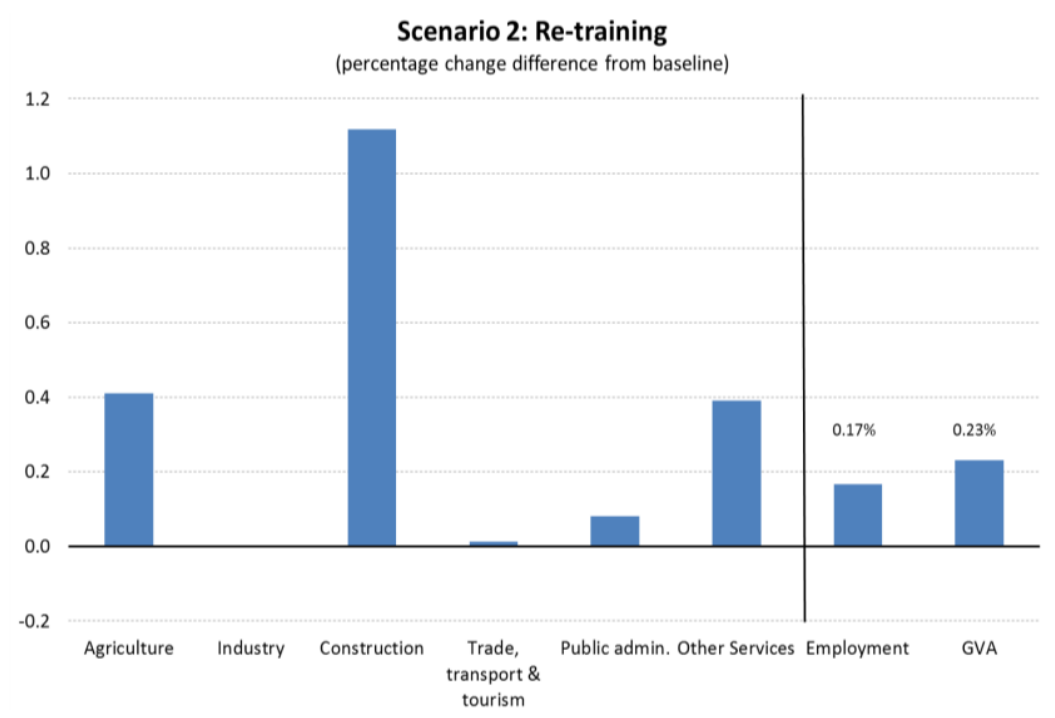

Figure 4. Re-training

\section{Scenario 3: Reduction in unemployed workers}

Active labour market policies targeted to reduce the unemployment include those that lower the search costs and increase the efficiency of the matching process between job seekers and prospective employers. Similarly, 'make work pay' initiatives could be targeted to reduce the welfare dependency of the unemployed and help them to re-enter the labour market. In Malta, the 'Youth Guarantee Scheme' was launched to target young people of less than 25 years and supports them with training, job exposure and personalised assistance.

Scenario 3 considers a 10\% reduction in the unemployed workers aged between 15 and 24 that are proportionally spread across the entire skill spectrum. Given the type of jobs that young unemployed in Malta are looking for, around 55\% are categorized as medium skilled, while the share of high and low skilled amount to $28 \%$ and $17 \%$, respectively. Among the medium term jobs, the largest share constitutes service and sales workers followed by clerical support workers.

In response to this shock, employment and output increase by $1.2 \%$ and $1.1 \%$, respectively. The sectors that benefit the most from the shift of unemployed workers into employment are the trade, transport and tourism industries, followed by other market services and, to a lesser extent, public administration, health and education. The result is broadly in line with our expectations given that slightly less than half the workers in trade, transport and tourism are service and sales workers and clerical support staff.

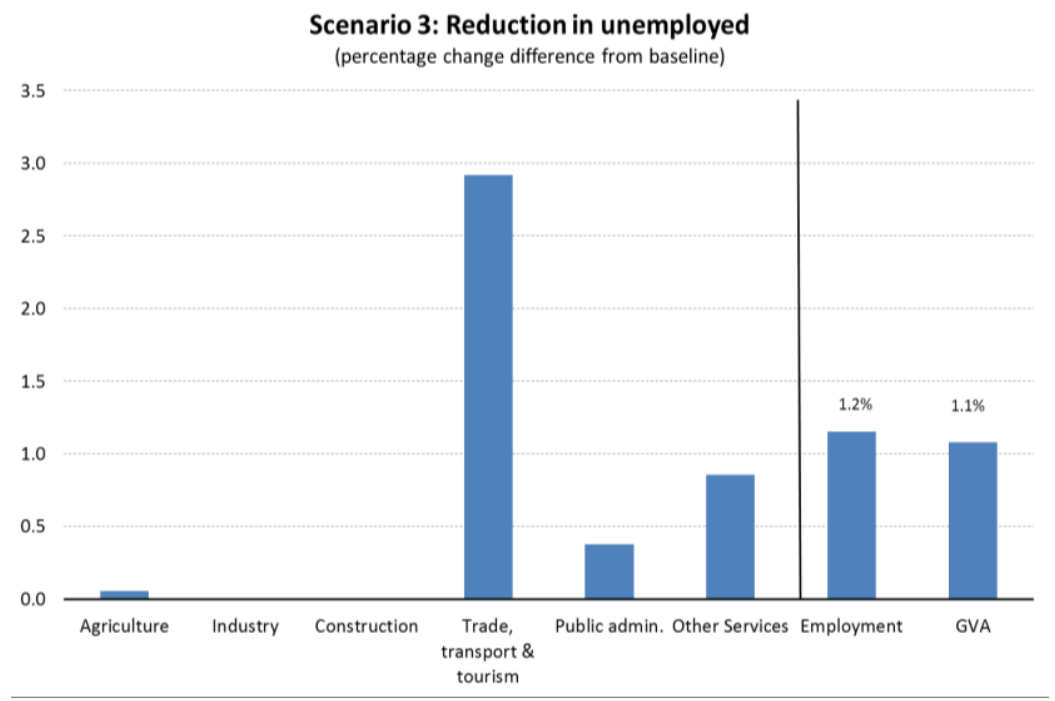

Figure 5. Active labour market policies 


\section{Scenario 4: Inflow of workers in the population}

Scenario 4 simulates a scenario in which a number of people are added to the population. In the model, this scenario is simulated by increasing the population with an amount equivalent to $1 \%$ of the labour force, which is distributed equally in two age brackets, the 25 to 34 and 35 to 44 . Given the importance of foreign workers in Malta, we make a further distinction between the inflow of low and high skilled persons. The former assumes an increase in persons with a low level of education (Scenario 4a) while the latter assumes that the inflow of new people has a tertiary level of education (Scenario 4b).

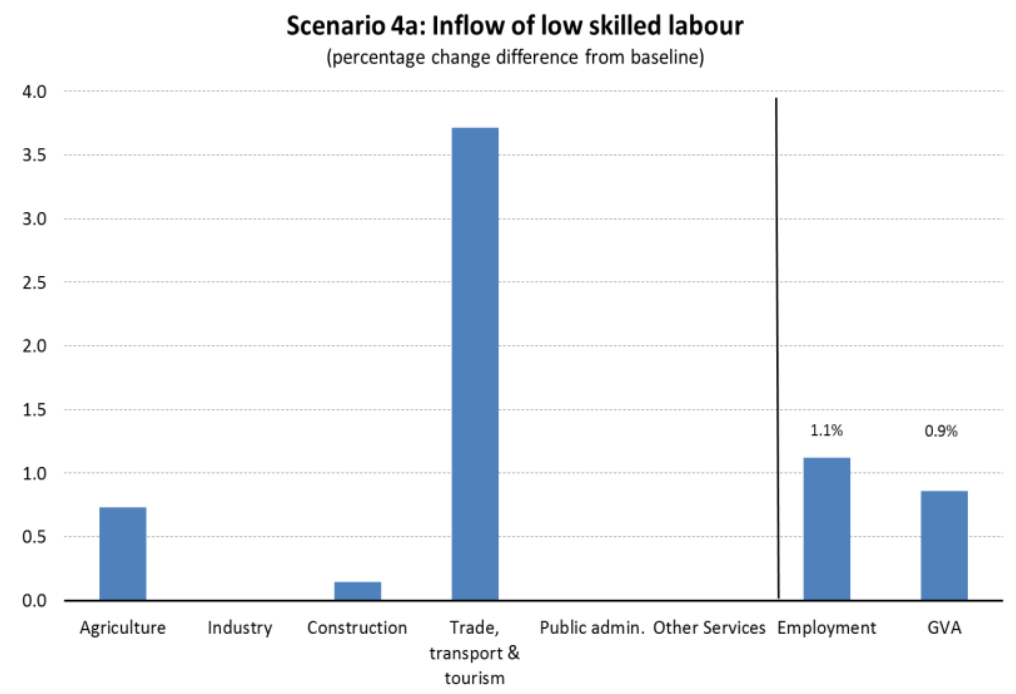

Figure 6. Inflow of low skilled labour

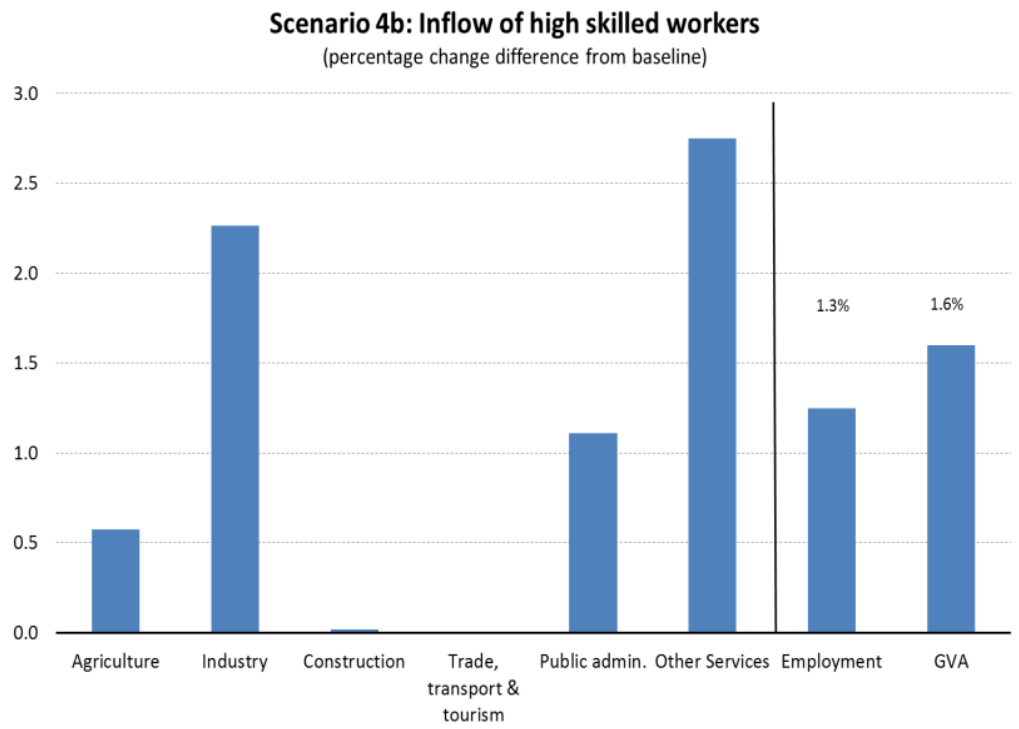

Figure 7. Inflow of high skilled workers

In response to Scenario $4 \mathrm{a}$, employment and output increase by $1.1 \%$ and $0.9 \%$, respectively, relative to baseline. Most of the increase is concentrated in trade, transport and the tourism sectors, followed by agriculture and construction. This result is not surprising given the large share of foreigners working in the tourism industry, such as in hotels and restaurants. On the contrary, one would have expected the construction sector to benefit more from such an inflow of low skilled workers given the prevalence of such workers in this industry. The latter result, however, may be influenced by the use of foreigners working in the underground economy.

The increases in both employment and output are more pronounced in the scenario involving high skilled inflows. In this case, employment increases by $1.3 \%$ compared to the baseline, while output rises by $1.6 \%$. Even the 
sectoral allocation is different. The sector that benefits the most is other market services, followed by manufacturing and the public administration, health and education. The large increase in other market services is in line with prior expectations given the prevalence of foreign workers in the remote gaming sector, professional services and administrative support activities (Grech, 2015). The manufacturing sector is also positively affected as the shift towards higher value-added activities industries observed in recent years has raised the demand for high skilled workers such as engineers and scientists. It is important to note that the increase in output in this scenario is almost double that of a similar inflow of low skilled workers as the sectors benefitting the most from this simulation, mainly other market services, have a higher value added per worker.

\section{Scenario 5: Outflow of workers from the population}

Scenario 5 simulates a hypothetical situation of an outflow of workers from the population. This could be due, for instance, to the foreign workers who work in the domestic economy returning to their home countries. In the model, this scenario is simulated by a reduction in the population equivalent to $1 \%$ of the labour force. In terms of the age distribution, $35 \%$ are assumed to be between $15-24,45 \%$ between $25-34$ and $20 \%$ in the $35-44$ age cohort. These persons are assumed to have a tertiary level of education.

As expected, this shock has an adverse effect on both employment and output, which decline by $0.9 \%$ and $1.0 \%$, respectively compared to the baseline scenario. All sectors are negatively affected, although most job losses are concentrated in other market services and public administration, health and education. This is not surprising given the prevalence of skilled foreign workers in other market services but also in the health sector.

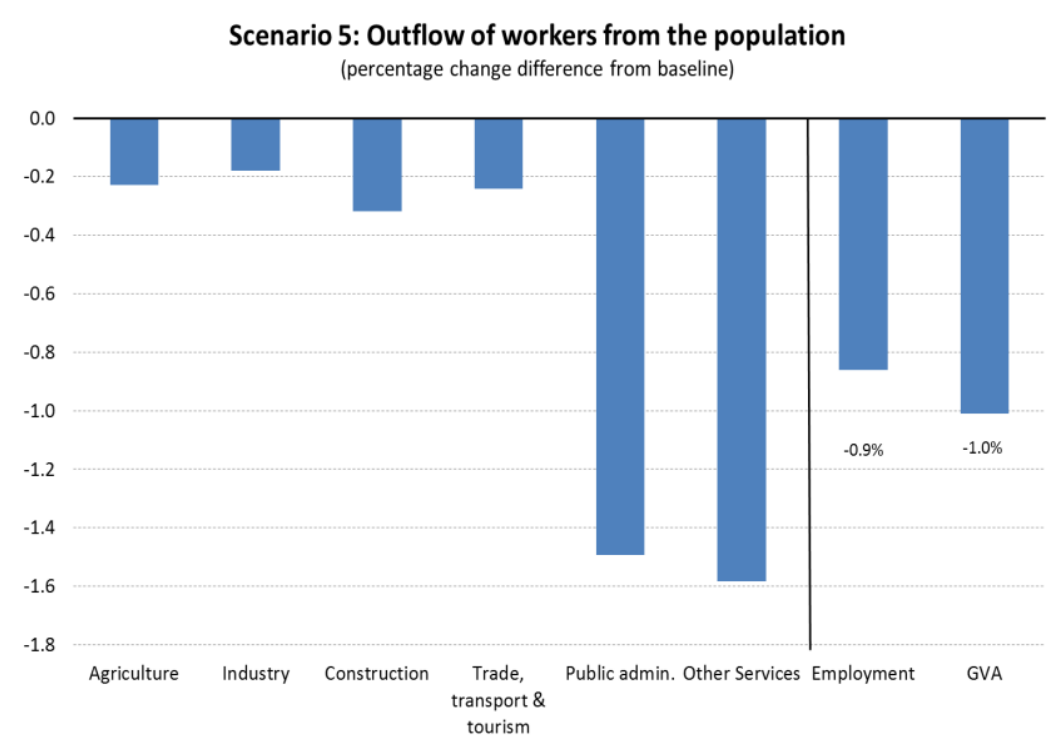

Figure 8. Outflow of workers from the population

\section{Discussion}

Overall, the model simulations provided plausible results on the effects of labour market policies on sectoral employment and economy-wide gross value added.

The simulation results point to the need to further strengthen the education system to ensure that workers are well-equipped with the skills required by industry and to avoid the risk of having a shortage of a sufficiently skilled workforce. Malta still has one of the highest percentages of early leavers from education and training among the EU countries, while the share of those with only a compulsory level of education is one of the highest in the EU (see Table 1). Furthermore, the share of 30 to 34 year old with a tertiary level of education remains around 10 percentage points lower than the EU average, while the number of science and technology graduates still lags behind its European peers.

On the positive side, the gap with the EU is gradually closing down. The setup of the Malta Council for Arts, Science and Technology (MCAST) in the early 2000s improved the low level of education attainment of the Maltese workforce. Linkages between industry and academia have also improved, thus ensuring that education and training programs are better tailored to suit the demand of the industries. In this regard, new apprenticeship and traineeship schemes that provide work exposure for students have been introduced that span various sectors, 
including manufacturing and financial services.

Improvements in education are associated with more active participation in the labour market, especially for females (Ministry for Social Policy, 2003). In recent years, the authorities have implemented various measures to raise the female participation rate in Malta, such as tax incentives and free childcare (Micallef, 2015). As a result, the female participation rate increased from $42.5 \%$ in 2010 to 53.8\% in 2015, though it still remains one of the lowest in the EU. Micallef (2015) attributes around half of this increase in the female participation rate to targeted government incentives. Table 1 shows that the gap between Malta and its European peers is mostly due to individuals with a low level of education, whereas the participation rate of women in Malta with an upper secondary or tertiary level of education is higher than in the EU. The model simulations confirm that the benefits, in terms of employment and output, from having a pool of human resources with tertiary education significantly outweigh those of having the same amount of resources with post-secondary education.

Table 1. Key labour market indicators

\begin{tabular}{|c|c|c|c|}
\hline & \multicolumn{2}{|c|}{ Malta } & \multirow{2}{*}{$\begin{array}{c}\text { EU } \\
2015\end{array}$} \\
\hline & 2010 & 2015 & \\
\hline \multicolumn{4}{|l|}{ Education and training } \\
\hline Early leavers from education and training & 23.8 & 19.8 & 11.0 \\
\hline At most lower secondary education attainment (25-64) & 67.0 & 56.5 & 23.5 \\
\hline Tertiary education attainment $(30-34)$ & 22.1 & 27.8 & 38.7 \\
\hline Science and technology graduates $(20-29)$ & 8.2 & $11.1^{*}$ & $17.1^{\circ}$ \\
\hline Life-long & 6.2 & 7.2 & 10.7 \\
\hline \multicolumn{4}{|l|}{ Unemployment } \\
\hline Unemployment rate & 6.9 & 5.4 & 9.4 \\
\hline Structural unemployment rate & 6.6 & 5.4 & 8.4 \\
\hline \multicolumn{4}{|l|}{ Activity rates } \\
\hline Activity rate & 60.4 & 67.6 & 72.5 \\
\hline Males & 77.8 & 80.8 & 78.3 \\
\hline $15-24$ & 53.6 & 53.3 & 44.1 \\
\hline $25-54$ & 94.5 & 95.4 & 91.4 \\
\hline ISCED (levels 0-2) & 92.8 & 93.6 & 84.3 \\
\hline ISCED (levels 3-6) & 97.4 & 97.1 & 92.1 \\
\hline ISCED (levels 5-8) & 96.6 & 97.3 & 95.6 \\
\hline $55-64$ & 52.3 & 62.1 & 65.0 \\
\hline Females & 42.5 & 53.8 & 66.8 \\
\hline $15-24$ & 48.1 & 49.8 & 38.7 \\
\hline $25-54$ & 50.6 & 65.8 & 79.4 \\
\hline ISCED (levels 0-2) & 33.6 & 43.9 & 60.7 \\
\hline ISCED (levels 3-6) & 72.2 & 81.4 & 80.2 \\
\hline ISCED (levels 5-8) & 89.2 & 92.9 & 89.0 \\
\hline $55-64$ & 14.6 & 22.6 & 50.0 \\
\hline \multicolumn{4}{|l|}{ Foreign workers } \\
\hline Share of foreign workers in workforce & 4.6 & $10.1^{* *}$ & \\
\hline
\end{tabular}

Attention should be directed not only to inputs, such as the amount of public expenditure on education, but more importantly on the output that the country is reaping from this expenditure. According to the European Commission (2008), at least the same level of tertiary level enrollment could be achieved with $77 \%$ of the present level of expenditure per student. The same study also finds that tertiary enrolment could increase significantly if educational spending is more efficient. These findings suggest that there is considerable scope for efficiency gains in the allocation of spending in tertiary education, which could lead to higher attainment levels in Malta.

The country has also managed to raise the participation rate of older workers, albeit from very low levels. From a longer-term perspective, however, the increase in the participation rate of older workers falls short of the increases seen in the EU. An important cause of this gap is the presence of early exit routes, such as disability benefits, although there is also an issue related with the skills and employability of this age group. The pension reform, in conjunction with targeted fiscal measures and measures to curtail abuse, should contribute to encourage more workers to remain active over the coming years. Average exit age from the labour market suggest that Malta is gradually closing the gap with the EU. For instance, the number of persons on invalidity pensions declined by around 46\% between 2004 and 2013 (Pension Strategy Group, 2015).

The increase in the supply of labour did not however eliminate the mismatch between the demand for and supply 
of skills, as well as shortages of labour in specific industries. These two concerns are widely considered to the main frictions in the Maltese labour market. Domestic employers regularly complain about the difficulties experienced in recruiting appropriate candidates to fill up vacancies requiring both skilled and unskilled workers. The reduction of the unemployment rate to historically low levels further reduces the pool of available workers for firms.

The strong growth in employment registered by the economy over the last few years was facilitated by an inflow of foreign workers, thereby easing skill mismatches and shortage of domestic labour faced by firms. The share of foreign workers in the workforce increased from $1.7 \%$ in 2004 to $10 \%$ a decade later. While foreign workers are spread across all sectors of economic activity, they are concentrated in both ends of the skill spectrum, the high skilled jobs, for which skills are scarce and the lower end, where jobs are no longer attractive for Maltese workers (Grech, 2015). It can be argued that in the absence of such influx of foreign workers, some industries in Malta would never have taken off as the required skills in key categories were not available locally. For instance, around one third of the workforce in the remote gaming sector is foreign. In three other sectors, administrative and support services, the hospitality industry and professional and technical activities, the share of foreign workers range between 10\% and 20\% (Ministry for Education and Employment, 2014). The composition of the foreign workforce has also changed significantly over the last decade. While in the early 2000s it was predominantly made up of managerial, professional and technical jobs, the share of elementary occupations and clerical and support staff increased to around a third of the total by 2014 .

The importance of foreign workers is further accentuated in the context of an ageing population, with a shrinking working age population translating into a lower pool of human resources available to meet the increasing demand. According to Grech (2015), Malta's working age population would have declined by $1 \%$ between 2004 and 2014 in the absence of migration. Instead, it rose by 3\%, thereby contributing to raising the economy's potential GDP growth. Besides their contribution to economic activity, foreign workers have also contributed to improve public finances, with the amount of revenue collected by foreigners increasing by nine-fold between 2000 and 2014.

\section{Conclusion}

This paper presents a novel modelling approach to characterize the supply side of the Maltese economy and uses this framework to quantitatively assess the economic impact of specific labour market policies. This approach differs from the current studies on the Maltese economy, which use an aggregate approach and generally abstract from developments at a sectoral level. The empirical model combines sectoral information with the characteristics of the workforce, such as age and education level, and can be used to assess a broad range of labour market reforms such as those pertaining to education and re-training, active labour market policies and inflows or outflows of workers from the labour market.

The modelling approach adopted here is subject to various assumptions and simplifications whose relaxation and further investigation can be the subject of further study. The principal ones are the following. First, a more in-depth analysis of labour market characteristics could be undertaken, including, for instance, distinction between male and female employment, and full- and part-time employment. Second, a more detailed sectoral analysis could be attempted, although this has to be weighed against the availability and reliability of data at a detailed level. Finally, dynamic effects could be introduced in the model to capture long term phenomena which take place over a prolonged period of time, such as population ageing. These avenues will be left for future research.

\section{References}

Bayoumi, T., Laxton, D., \& Pesenti, P. (2004). Benefits and spillovers of greater competition in Europe: A macroeconomic assessment. ECB Working Paper 341. https://doi.org/10.2139/ssrn.551643

Blanchard, O., \& Giavazzi, F. (2003). The macroeconomic effects of regulation and deregulation in goods and labour markets. The Quarterly Journal of Economics, 118(3), 879-909. https://doi.org/10.1162/00335530360698450

Bugeja, S., Mifsud, G., \& Saliba, P. (2016). Research Note: Illustrating the distributiona implications of measures from the 2016 Budget for Malta. EUROMOD Working Paper EM12/16.

Cotis, J. P., Elmenskov, J., \& Mourougane, A. (2003). Estimates of potential output: benefits and pitfalls from a policy perspective. OECD economic department.

European Commission. (2008). Public finances in EMU - 2008. 
Everaert, L., \& Schule, W. (2008). Why it pays to synchronize structural reforms in the euro area across markets and countries. IMF Staff Papers, (55), 2. https://doi.org/10.1057/imfsp.2008.6

Forni, L., Gerali, A., \& Pisani, M. (2010). Macroeconomic effects of greater competition in the services: The case of Italy. Macroeconomics Dynamics, 14(5), 677-708. https://doi.org/10.1017/S1365100509990800

Gomes, S., Jacquinot, P., Mohr, M., \& Pisani, M. (2011). Structural reforms and macroeconomic performance in the euro area countries: A model-based assessment. ECB Working Paper 1323. https://doi.org/10.2139/ssrn.2004402

Grech, A. G. (2015). Understanding the macroeconomic impact of migration in Malta. Central Bank of Malta Policy Note, December 2015.

Grech, A. G. (2016). The possible impact of pension age changes on Malta's potential output. Central Bank of Malta Policy Note, April 2016.

Grech, A. G., \& Micallef, B. (2015). Assessing the supply side of the Maltese economy using a production function approach. Xjenza, 3(1), 57-63. https://doi.org/10.7423/XJENZA.2015.1.08

Lopez-Garcia, P., di Mauro, F., \& CompNet Task Force. (2015). Assessing European competitiveness: The new CompNet micro-based database. ECB Working Paper 1764.

Lusinyan, L., \& Muir, D. (2013). Assessing the macroeconomic impact of structural reforms: The case of Italy. IMF Working Paper WP/13/22. https://doi.org/10.5089/9781475530865.001

Micallef, B. (2013). Measuring the effects of structural reforms in Malta: An analysis using the EAGLE model. Central Bank of Malta Working Paper WP/01/2013

Micallef, B. (2015). Estimating the impact on potential output of structural reforms to increase the female participation rate. Central Bank of Malta Policy Note, November 2016.

Micallef, B. (2016). A multivariate filter to estimate potential output and NAIRU for the Maltese economy. International Journal of Economics and Finance, 8(5), 13-22. https://doi.org/10.5539/ijef.v8n5p13

Micallef, B. (2017). Empirical estimates of Okun's Law in Malta. Applied Economics and Finance, 4(1), 138-148. https://doi.org/10.11114/aef.v4il.1930

Micallef, B., \& Caruana, K. (2015). Results of the 2014 Wage Dynamics Network for Malta. Publication available from the ECB WDN webpage.

Ministry for Education and Employment. (2014). The National Employment Policy. Publication available from the Employment and Training Corporation (ETC) website.

Ministry for Social Policy. (2003). Factors affecting women's formal participation in the Malta labour market: Results of a research project. Publication in collaboration with the University of Malta.

Mishkin, F. (2007). Estimating potential output, Speech delivered at the Conference on Price Measurement for Monetary Policy. Federal Reserve Bank of Dallas, May 24.

Pension Strategy Group. (2015). A strategy for an adequate and sustainable Maltese pension system. Retrieved from https://socialpolicy.gov.mt/en/Pensions-Reform/Documents/Pensions\%20Report.pdf

Smets, F., \& Wouters, R. (2007). Shocks and frictions in the US business cycle: A DSGE approach. American Economic Review, 97(3), 586-606. https://doi.org/10.1257/aer.97.3.586

\section{Notes}

Note 1. Mishkin (2007) provides a non-technical overview of the main approaches used in the literature and their relevance for policymakers.

Note 2. In addition, sectoral price deflators are not available in Malta.

\section{Copyrights}

Copyright for this article is retained by the author(s), with first publication rights granted to the journal.

This is an open-access article distributed under the terms and conditions of the Creative Commons Attribution license (http://creativecommons.org/licenses/by/4.0/). 